\title{
PENGEMBANGAN BAHAN AJAR KIMIA KONTEKSTUAL TERINTEGRASI KEISLAMAN
}

\author{
Devi Qurniati ${ }^{{ }^{*}}$ \\ ${ }^{1}$ Program Studi Tadris Kimia Fakultas Tarbiyah dan Keguruan Universitas Islam Negeri Mataram, \\ NTB Indonesia \\ * Corresponding author: chemistrydevi@uinmataram.ac.id
}

Received: 27 Februari 2021

Accepted: 12 Juli 2021

Published: 14 Agustus 2021

doi: $10.29303 /$ cep.v4i2.2535

\begin{abstract}
Abstrak
Pengembangan bahan ajar di sekolah harus disesuaikan dengan kurikulum, dimana kurikulum 2013 adalah kurikulum yang diterapkan saat ini. Yang ditekankan dalam Kurikulum 2013 adalah dimensi pedagogik modern, sehingga dalam kurikulum 2013 menggunakan pendekatan ilmiah. Prinsip pendekatan saintifik selaras dengan pendekatan kontekstual sehingga materi yang dipelajari siswa dapat diterapkan dalam kehidupan mereka. Selain siswa dapat menerapkan materi kimia dalam kehidupan, siswa juga harus memiliki keimanan dan ketakwaan kepada Allah SWT. Untuk itu perlu dilakukan pengembangan bahan ajar yang kontekstual dan terintegrasi keislaman. Tujuan Penelitian ini adalah mengetahui kualitas bahan ajar yang dikembangkan yaitu bahan ajar kimia kontekstual dan terintegrasi keislaman materi Ikatan Kimia kelas X SMA/MA. Bahan ajar ini dikembangkan menggunakan model ADDIE dengan tahapan antara lain analisis, desain, pengembangan, implementasi dan evaluasi bahan ajar. Bahan ajar yang diperoleh sangat layak digunakan delam pembelajaran kimia, hal tersebut berdasarkan pada penilaian bahan ajar yang dilakukan oleh ahli media dengan nilai sangat baik, ahli materi dengan nilai sangat baik, ahli agama dengan nilai sangat baik, guru mata pelajaran kimia dengan nilai sangat baik, dan menurut tanggapan siswa sangat baik. Berdasarkan penilaian tersebut maka bahan ajar kimia kontekstual dan terintegrasi keislaman layak digunakan dalam pembelajaran.
\end{abstract}

Kata kunci: Pengembangan bahan ajar, kontekstual, terintegrasi keislaman.

\section{Development of Islamic Integrated Contextual Chemical Teachings}

\begin{abstract}
The development of teaching materials in schools must be adjusted to the curriculum, where the 2013 curriculum is the current curriculum. The emphasis in the 2013 curriculum is the modern pedagogical dimension, so that the 2013 curriculum uses a scientific approach. The principles of the scientific approach are in line with the contextual approach so that the material students learn can be applied in their lives. In addition to students being able to apply chemical materials in life, students must also have faith and devotion to Allah SWT. For this reason, it is necessary to develop contextual and integrated Islamic teaching materials. The purpose of this study was to determine the quality of the teaching materials developed, namely contextual chemistry teaching materials and integrated Islamic chemistry materials for class X SMA/MA. This teaching material was developed using the ADDIE model with stages including analysis, design, development, implementation and evaluation of teaching materials. The teaching materials obtained are very suitable for use in chemistry learning, this is based on the assessment of teaching materials carried out by media experts with very good grades, material experts with very good grades, religious experts with very good grades, chemistry subject teachers with very good grades, and according to the students' responses are very good. Based on this assessment, contextual and integrated Islamic chemistry teaching materials are suitable for use in learning.
\end{abstract}

Keywords: Development of teaching materials, contextual, Islamic integration. 


\section{Chemistry Education Practice, 4 (2), 2021 - 187}

Qurniati

\section{PENDAHULUAN}

Kegiatan belajar mengajar merupakan proses komunikasi yang melibatkan guru, siswa dan materi pelajaran. Dalam proses pembelajaran terkadang terjadi kegagalan komunikasi, dimana materi pelajaran yang disampaikan guru tidak dapat diterima siswa secara optimal. Belajar merupakan akibat adanya proses interaksi antara stimulus dan respon. Perubahan perilaku dapat menunjukkan seseorang telah belajar. Proses pembelajaran tidak lepas dari sumber belajar, untuk itu guru perlu menetapkan sumber belajar agar tujuan pembelajaran dapat tercapai (Sanjaya, 2006). Bahan ajar dapat digunakan sebagai salah satu sumber belajar dalam pembelajaran (Prastowo, 2012). Bahan ajar adalah segala bentuk bahan yang dapat mendukung kegiatan belajar mengajar dikelas (Amri, 2010). Maka diperlukan bahan ajar yang tepat sehingga bisa digunakan siswa (Suyanti, 2010). Bahan ajar memiliki banyak bentuk antara lain bahan cetak, audio visual, audio, visual, dan multi media.

Bahan ajar dapat dikembangkan untuk mencapai tujuan pembelajaran. Pengembangan bahan ajar di sekolah harus disesuaikan dengan kurikulum, dimana kurikulum 2013 adalah kurikulum yang diterapkan saat ini. Yang ditekankan dalam Kurikulum 2013 adalah dimensi pedagogik modern, sehingga dalam kurikulum 2013 menggunakan pendekatan ilmiah (Kemendikbud, 2013). Prinsip pendekatan saintifik selaras dengan pendekatan pembelajaran kontekstual (Rimbawati, 2014). Dalam pendekatan kontekstual, siswa banyak dilibatkan dalam aktivitas pembelajaran, karena dalam pendekatan ini siswa dapat menemukan sendiri materi yang dipelajari dan siswa juga dapat menghubungkan materi yang dipelajari dengan kehidupan nyata siswa (Komalasari, 2013), sehingga siswa dapat menerapkan materi yang telah dipelajari dalam kehidupan mereka (Sanjaya, 2006).

Dalam pembelajaran, siswa tidak hanya dapat menerapkan materi kimia dalam kehidupan, namun siswa juga harus memiliki keimanan dan ketakwaan kepada Allah SWT. Hal ini berdasarkan peraturan pemerintah tentang penyelenggaraan pendidikan no 17 tahun 2010 dimana siswa harus dapat berkembang menjadi manusia yang memiliki keimanan dan ketakwaan kepada Allah SWT serta memiliki akhlak yang mulia. Untuk mencapai tujuan tersebut, perencanaan pembelajaran yang baik perlu dilakukan yaitu perencanaan bahan ajar yang dapat mengintegrasikan nilai-nilai keislaman. Integrasi materi kimia dengan Al-Quran dan hadits diharapkan dapat menambah keimanan dan ketakwaan siswa. Integrasi islam dan sains dalam pembelajaran menjadikan siswa lebih mengenal penciptanya dan ciptaan-Nya serta membuat siswa berfikir kritis terhadap fenomena sains (Purwanto, 2008). Mengeksplorasi Alquran dan hadits menjadi landasan keilmuan dapat mengintegrasikan ilmu umum dengan ilmu agama. Integrasi tersebut bertujuan agar memperoleh kebenaran berdasarkan Al-quran dan hadits dan dapat menciptakan ilmu yang koheren dengan ajaran agama (Ramzi, 2004).

Pengembangan bahan ajar telah banyak dilakukan, diantaranya mengembangkan bahan ajar yang berbasis kontekstual pada materi Himpunan (Purwanto Y. , 2015), dan mengembangkan bahan ajar matematika yang terintegrasi nilai Keislaman (Fadhlun, 2017) (Branch, 2009). Namun pengembangan bahan ajar kimia yang kontekstual dan terintegrasi keislaman belum dilakukan. Berdasarkan uraian di atas maka peneliti akan melakukan penelitian yang berjudul "Pengembangan Bahan Ajar Kimia Kontekstual Terintegrasi Keislaman"

\section{METODE}

Penelitian ini merupakan penelitian pengembangan (Research and Development). Bahan ajar kimia kontekstual terintegrasi keislaman dikembangkan dengan menggunakan tahapan model pengembangan ADDIE. Model ADDIE memiliki 5 tahapan yaitu (1) Analisis bahan ajar; (2) Desain bahan ajar; (3) Pengembangan bahan ajar; (4) Implementasi bahan ajar; dan (5) Evaluasi bahan ajar (Branch, 2009).

Uji coba dilakukan dalam beberapa tahap, antara lain (1) review ahli isi dan review ahli media, (2) uji coba siswa dalam kelompok kecil, (3) uji coba lapangan. Adapun uji coba hasil pengembangan bahan ajar dilakukan pada siswa kelas X MA Putri Al-Ishlahuddiny dimana 9 orang siswa pada uji coba kelompok kecil dan 30 orang siswa pada uji coba lapangan.

Data-data yang dihasilkan dalam penelitian ini terbagi menjadi tiga bagian, antara lain:

1) Data hasil uji ahli isi dan ahli media.

2) Data hasil uji kelompok kecil

3) Data hasil uji lapangan.

Instrumen yang digunakan dalam penelitian ini adalah angket Data-data tersebut dianalisis menggunakan teknik analisis deskriptif 
kualitatif dan analisis statistik deskriptif. Informasi-informasi yang berupa masukan, tanggapan, kritik, dan saran perbaikan dari ahli materi, ahli media pembelajaran, dan tanggapan siswa diolah menggunakan teknik analisis deskriptif kualitatif. Sedangkan data yang diperoleh melalui angket diolah menggunakan teknik analisis statistik deskriptif.

Untuk menghitung persentase penilaian dari ahli materi dan ahli media digunakan rumus berikut (Arikunto, 2006):

Keterangan:

$$
P=\frac{\sum x i}{\sum x} x 100 \%
$$

$P \quad=$ Presentase penilaian

$\sum \mathrm{xi}=$ Jumlah jawaban

$\sum \mathrm{x}=$ Jumlah jawaban tertinggi.

Untuk mengetahui respon siswa terhadap bahan ajar menggunakan rumus persentase kelayakan berikut:

$$
K=\frac{F}{N x I x R} \times 100 \%
$$

Keterangan:

$\mathrm{K}=$ persentase kelayakan

$\mathrm{F}=$ jumlah keseluruhan penilaian

$\mathrm{N}=$ jumlah penilaian tertinggi

$\mathrm{I}=$ jumlah butir penilaian

$\mathrm{R}=$ jumlah siswa

Hasil perhitungan di atas dilakukan untuk menentukan tingkat kelayakan bahan ajar yang dikembangkan, dengan mengacu pada tabel 1 di bawah ini:

Tabel 1. Konversi Tingkat Kelayakan Bahan Ajar

\begin{tabular}{ccl}
\hline No. & Persentase (\%) & \multicolumn{1}{c}{ Kriteria } \\
\hline 1. & $81-100$ & Sangat baik \\
2. & $61--80$ & Baik \\
3. & $41-60$ & Kurang baik \\
4. & $21-40$ & Tidak baik \\
5. & $0-20$ & Sangat tidak baik \\
\hline
\end{tabular}

(Riduwan, 2013)

\section{HASIL DAN PEMBAHASAN}

Beberapa hasil yang diperoleh dalam penelitian pengembangan bahan ajar kimia kontekstual terintegrasi keislaman ini anatara lain:

1. Sebuah media pembelajaran berupa bahan ajar kimia kontekstual terintegrasi keislaman untuk materi ikatan kimia.

2. Hasil penilaian yang diperoleh dari ahli materi dan ahli media.terhadap produk bahan ajar kimia kontekstual terintegrasi keislaman pada materi ikatan kimia
3. Tanggapan dan penilaian dari guru terhadap bahan ajar kimia kontekstual terintegrasi Keislaman..

4. Respon siswa terhadap bahan ajar kimia kontekstual terintegrasi keislaman dengan menyebarkan angket kepada siswa MA Putri Al-Ishlahuddiny.

Beberapa hasil yang dipeoleh dalam setiap tahapan model pengembangan ADDIE antara lain:

\section{Analisis Bahan Ajar}

Pada Tahap ini dilakukan dengan kegiatan observasi, wawancara dan pengisian angket. Dua hal yang dilakukan penulis dalam tahap ini yaitu analisis kebutuhan, dan analisis kurikulum. Untuk menganalisis keadaan dan bahan ajar yang tersedia dalam mendukung kegiatan pembelajaran dilakukan analisis kebutuhan. Hasil yang diperoleh pada analisis kebutuhan ini antara lain bahan ajar yang digunakan oleh guru kimia di MA Putri AlIshlahuddiny yaitu menggunakan bahan ajar (LKS) yang diperjualbelikan oleh beberapa penerbit yang tidak kontekstual dan tidak mengandung nilai-nilai keislaman. Adapun untuk mengetahui kurikulum yang digunakan di MA Putri Al-Ishlahuddiny dilakukan analisis kurikulum. Kurikulum yang digunakan di MA Putri Al-Ishlahuddiny adalah kurikulum 2013. Selain itu, pada tahap ini, dilakuakn analisis Kompetensi Inti (KI) dan Kompetensi Dasar (KD) pada kelas $\mathrm{X}$ yaitu materi ikatan kimia untuk merumuskan tujuan pembelajaran.

\section{Desain Bahan Ajar}

Pada tahap ini dilakukan perancangan bahan ajar yang dikembangkan yaitu menentukan kerangka bahan ajar yaitu bagian-bagian yang terdapat dalam bahan ajar. Adapun bagian-bagian dalam bahan ajar kimia kontekstual terintegrasi keislaman terdapat pada tabel 2.

\begin{tabular}{|c|c|c|}
\hline No. & $\begin{array}{c}\text { Bagian dalam bahan } \\
\text { ajar }\end{array}$ & Keterangan \\
\hline 1. & $\begin{array}{l}\text { Pemetaan Kompetensi } \\
\text { inti (KI), Kompetensi } \\
\text { dasar (KD), Indikator } \\
\text { dan Tujuan } \\
\text { pembelajaran }\end{array}$ & $\begin{array}{l}\text { Berisi tentang KI, } \\
\text { KD indikator dan } \\
\text { Tujuan } \\
\text { pembelajaran }\end{array}$ \\
\hline 2. & $\begin{array}{l}\text { Rencana Pelaksanaan } \\
\text { Pembelajaran (RPP) }\end{array}$ & $\begin{array}{l}\text { Berisi rencana } \\
\text { guru dalam } \\
\text { mengajarkan } \\
\text { materi }\end{array}$ \\
\hline 3. & Peta Konsep & $\begin{array}{l}\text { Berisi alur } \\
\text { berfikir ketika }\end{array}$ \\
\hline
\end{tabular}

Tabel 2. Bagian-bagian Bahan Ajar 


\begin{tabular}{|c|c|c|}
\hline \multirow{5}{*}{4.} & \multirow{5}{*}{ Simak Yuk } & $\begin{array}{l}\text { mempelajari } \\
\text { materi kimia }\end{array}$ \\
\hline & & Berisi materi \\
\hline & & kimia yang \\
\hline & & kontekstual \\
\hline & & Berisi materi \\
\hline 5. & Tahukah Kamu & $\begin{array}{l}\text { kimia yang } \\
\text { terintegrasi } \\
\text { keislaman }\end{array}$ \\
\hline 6. & Ayo Belajar & $\begin{array}{l}\text { Berisi materi } \\
\text { kimia }\end{array}$ \\
\hline 7 & Ayo Diskusi & $\begin{array}{l}\text { Berisi arahan } \\
\text { untuk diskusi agar } \\
\text { siswa terbiasa } \\
\text { melakukan } \\
\text { diskusi }\end{array}$ \\
\hline 8 & Rangkuman & $\begin{array}{l}\text { Berisi ringkasan } \\
\text { materi agar siswa }\end{array}$ \\
\hline 9 & Ayo Berfikir & $\begin{array}{l}\text { Berisi soal latihan } \\
\text { yang akan } \\
\text { dikerjakan siswa }\end{array}$ \\
\hline
\end{tabular}

Materi dalam bahan ajar diketik dengan format Arial, dan ukuran bahan ajar menggunakan kertas A5. Pada tahap ini, dilakukan pengumpulan dan pembuatan background, cover dan layout bahan ajar serta menyusun instrumen yang digunakan untuk menilai kelayakan bahan ajar yang berupa angket penilaian validasi ahli materi kimia dan agama, ahli media dan angket siswa dalam uji kelompok kecil dan uji lapangan.

\section{Pengembangan Bahan Ajar}

Pada tahap ini dilakukan pengembangan bahan ajar yang sesuai dengan rancangan yaitu bahan ajar kimia yang kontekstual dan terintegrasi keislaman pada materi ikatan kimia, sehingga tahap ini disebut tahap realisasi produk.

Materi ikatan kimia yang kontekstual dalam bahan ajar adalah sebagai berikut: ikatan ion, kestabilan unsur, ikatan kovalen, ikatan logam, ikatan kovalen koordinasi, ikatan kovalen polar dan nonpolar. Beberapa contoh materimateri tersebut yang kontekstual antara lain manfaat air dalam kehidupan, sabun dan detergen yang dipakai dalam kehidupan sehari-hari, kehidupan koloni semut, mekanisme pernafasan pada manusia, lampu pijar yang digunakan sebagai sumber penerangan, penggunaan pupuk dalam pertanian, penggunaan betadin ketika luka, dan permainan kembang api yang dilakukan oleh anak-anak.

Materi ikatan kimia yang terintegrasi keislaman dalam bahan ajar antara lain: konsep ion positif dan ion negatif, konfigurasi elektron yang stabil, teori pembentukan ikatan kimia, ikatan ion, ikatan kovalen non polar, ikatan kovalen polar, ikatan kovalen koordinasi, ikatan hydrogen dan ikatan logam. Materi-materi tersebut dikaitkan dengan syariat islam. Adapun syariat islam yang terkait dengan teori ikatan kimia antara lain yaitu zakat, Pernikahan dalam islam, ta'ziyah, Silaturahmi, syirkah, muzara'ah dan mukhabarah. Sedangkan nilai keislaman yang terdapat dalam syariat islam tersebut yang berkaitan dengan konsep dan teori ikatan kimia adalah kerjasama dan solidaritas sosial antar sesama muslim yang dapat memperkuat ukhuwah islamiyah, saling membantu dan berbagi antar sesama muslim sehingga dapat mensejahterakan kehidupan sesama, serta saling memberi dan menerima untuk hidup bersama sebagai ketaatan manusia kepada pencipta-Nya.

Penjelasan materi ikatan kimia yang terintegrasi keislaman dapat dijelaskan sebagai berikut:

a. Konsep pernikahan dalam islam memiliki persamaan konsep dengan teori ikatan kimia yaitu adanya persamaan konsep yang mendasarinya. Pada teori ikatan kimia, terbentuknya ikatan kimia karena terdapat atom yang saling memberi dan menerima untuk mencapai konfigurasi elektron gas mulia yang stabil (Prasetiawan, 2008). Atomatom yang berikatan lebih stabil dari pada atom dalam keadaan sendiri (Prasetiawan, 2008) Jika dalam berikatan suatu atom dapat mencapai konfigurasi elektron yang stabil, dalam pernikahanpun seseorang akan memiliki ketenangan jiwa dan kemantapan batin karena dengan menikah sesorang dapat memiliki keturunan yang dapat melanjutkan risalah dakwahnya, dapat menegakkan rumah tangga islami dan dapat meningkatkan ibadah kepada Allah SWT. Adapun Nilai keislaman yang terkandung dalam pernikahan yang berkaitan dengan konsep kestabilan adalah saling memberi dan saling menerima untuk hidup bersama membentuk rumah tangga islami sebagai wujud ketaatan kepada Allah SWT.

b. Konsep zakat dalam agama islam memiliki keterkaitan dengan konsep ikatan ion dimana suatu atom akan berusaha untuk mencapai konfigurasi yang stabil seperti gas mulia yaitu dengan cara serah terima elektron (Akhmad, 1992). Misalnya atom Natrium melepaskan satu elektron terluarnya membentuk ion positif $\left(\mathrm{Na}^{+}\right)$yang sesuai dengan konfigurasi elektron unsur gas mulia yaitu neon; sedangkan atom $\mathrm{Cl}$ menerima satu elektron, 
membentuk ion negatif $\mathrm{Cl}^{-}$yang sesuai dengan konfigurasi elektron gas mulia seperti argon. Kedua ion tersebut saling tarik menarik secara elektrostatik dalam kisi ion. Serah terima elektron yang terjadi dari penggabungan kedua cara di atas disebut ikatan ion (Baum, 1980). Jika dalam ikatan ion, atom-atom melakukan serah terima elektron untuk mencapai kestabilan, dalam zakatpun seseorang dapat memberikan sebagian harta mereka kepada orang lain yang berhak menerima zakat. Dengan berzakat seseorang telah menjalankan perintah Allah SWT sehingga akan mendapatkan ganjaran pahala dari Allah SWT. Adapun nilai keislaman yang terdapat dalam zakat yang berkaitan dengan materi ikatan ion adalah saling membantu dan berbagi antar sesama muslim sehingga dapat mensejahterakan kehidupan sesama.

c. Konsep syirkah dalam agama islam memiliki keterkaitan dengan konsep ikatan kovalen dimana ikatan kovalen terbentuk karenai dua atom atau lebih yang menggunakan elektron secara bersama (Baum, 1980). Misalnya dalam senyawa $\mathrm{HCl}$, atom $\mathrm{Cl}$ menjadi stabil dengan menggunakan bersama satu pasang elektron dengan atom hidrogen. Ikatan kovalen terbentuk karena adanya gaya tarik menarik antara dua atom sebagai hasil dari berbagi antara satu atau lebih elektron pada kulit terluar oleh kedua atom (Baum, 1980). Konsep berbagi tersebut yang menjadi konsep dasar dari teori pembentukan ikatan kovalen sejalan dengan konsep syirkah dalam islam. Jika dalam ikatan kovalen atom-atom menggunakan pasangan elektron secara bersama untuk mencapai konfigurasi elektron yang stabil, dalam syirkahpun seseorang dapat bekerjasama dengan orang lain dalam hal modal untuk memperoleh keuntungan bersama sehingga dengan melakukan syirkah dapat mewujudkan kesejahteraan. Adapun nilai keislaman yang terdapat dalam syirkah yang berkaiatan dengan materi ikatan kovalen adalah kerjasama antar sesama muslim yang dapat memperkuat ukhuwah islamiyah.

d. Konsep muzaraah dan mukhabarah sejalan dengan konsep ikatan kovalen koordinasi dimana terdapat pasangan elektron yang dipakai bersama, namun pasangan elektron tersebut berasal dari salah satu atom (Effendy, 2016). Contohnya, senyawa $\mathrm{NH}_{3}$ (Amonia) yang dapat bereaksi dengan $\mathrm{BF}_{3}$ (Borin triflorida) membentuk senyawa $\mathrm{NH}_{3} \mathrm{BF}_{3}$. Atom $\mathrm{N}$ dalam $\mathrm{NH}_{3}$ telah stabil memenuhi aturan oktet dan memiliki satu pasang elektron bebas, sedangkan atom $\mathrm{B}$ dalam $\mathrm{BF}_{3}$ telah menggunakan semua elektronnya tapi belum memenuhi aturan oktet. Maka atom $\mathrm{N}$ dalam $\mathrm{NH}_{3}$ dan atom $\mathrm{B}$ dalam $\mathrm{BF}_{3}$ dapat berikatan membentuk molekul $\mathrm{NH}_{3} \mathrm{BF}_{3}$ dengan cara menggunakan elektron bebas atom $\mathrm{N}$ secara bersama. Ikatan tersebut yang disebut adalah ikatan kovalen koordinasi. Jika dalam ikatan kovalen koordinasi atom-atom berikatan dengan menggunakan elektron dari salah satu atom agar stabil, dalam muzaraah dan mukhabarahpun pemilik sawah dan penggarap sawah melakukan kerjasama untuk memperoleh keuntungan bersama, dimana muzaraah dengan modal biaya dan benih berasal dari penggarap sawah sedangkan mukhabarah modal biaya dan benih berasal dari pemilik tanah. Nilai keislaman yang terkandung dalam Muzaraah dan Mukhabarah yang berkaitan dengan ikatan kovalen koordinasi adalah kerjasama antara sesama muslim untuk memperoleh kesejahteraan hidup serta dapat memperkuat ukhuwah islamiyah.

e. Konsep silaturahmi sejalan dengan konsep terbentuknya ikatan kovalen polar dimana terdapat dua atom non logam berikatan yang memiliki perbedaan keelektronegatifan, sehingga pasangan elektron ikatan akan lebih tertarik ke atom yang memiliki keelektronegatifan yang lebih besar, ikatan kovalen non polar dimana terdapat dua atom non logam yang memiliki perbedaan keelektronegatifan yang kecil berikatan (Chang, 2004), serta teori Gilbert Lewis yaitu atom bergabung untuk mencapai konfigurasi elektron yang lebih stabil seperti gas mulia (Tupamahu, 2001). Jika dalam ikatan kovalen polar dan nonpolar atom-atom berikatan berdasarkan keelektronegatifan untuk mencapai konfigurasi elektron yang stabil, maka dalam silaturahmipun seseorang menjalin hubungan baik dengan orang lain sebagai ketaatan kepada Allah SWT untuk mendapatkan ganjaran pahala dari Allah SWT. Adapun nilai keislaman yang terkandung dalam silaturahmi yang berkaitan dengan konsep ikatan kovalen polar dan nonpolar adalah adalah kerjasama dan solidaritas sosial antar sesama muslim yang dapat memperkuat ukhuwah islamiyah.

f. Konsep pernikahan dalam islam berkaitan dengan konsep pembentukan ikatan logam, karena ikatan logam terbentuk karena adanya 
daya tarik menarik antara ion positif dan ion negatif (Wibraham, 1992). Kaitan konsep ikatan logam dengan konsep pernikahan dalam islam adalah mempelai wanita membuat keputusan sendiri untuk menikah tanpa ada pemaksaan dari orang lain pada acara khitbah atau lamaran. Dua atom atau lebih dalam berinteraksi, disertai dengan pengeluaran energi (Wibraham, 1992). Konsep pengeluaran energi berkaitan dengan adanya mahar dalam pernikahan. Jika dalam ikatan logam terjadi gaya tarik menarik antara muatan positif dengan muatan negatif, dalam pernikahanpun terjadi hubungan suci antara laki-laki dan perempuan yang suka sama suka tanpa paksaan, dimana dalam pernikahan terjadi kerjasama yang baik dan kuat antara suami dan istri sehingga terbentuk rumah tangga yang islami. Adapun Nilai keislaman yang terkandung dalam pernikahan yang berkaitan dengan konsep logam adalah saling memberi dan saling menerima tanpa paksaan untuk membentuk rumah tangga islami sebagai wujud ketaatan kepada Allah SWT.

g. Keterkaitan takziyah dengan teori ikatan kimia yaitu ikatan hidrogen yang terjadi diantara beberapa molekul, dimana atomatom dalam molekul tersebut mempunyai perbedaan elektronegatifitas tinggi. Atom yang mempunyai elektronegatifitas tersebut terikat pada atom $\mathrm{H}$ dalam molekul lain sehingga terbentuk rantai ikatan beberapa molekul (Akhmad, 1992). Pada acara takziyah,keluarga yang ditinggalkan menjadi pusat orang yang melayat karena keluarga yang ditinggalkan butuh untuk dihibur agar ikhlas dan sabar. Konsep ini sejalan dengan teori terbentuknya ikatan hidrogen, dimana yang menjadi pusat atau penentu terjadinya ikatan hidrogen adalah atom hidrogen. Jika dalam ikatan hidrogen terjadi ikatan antara beberapa molekul, dimana atom-atom dalam molekul tersebut mempunyai perbedaan elektronegatifitas tinggi dan atom yang mempunyai elektronegatifitas tersebut terikat pada atom $\mathrm{H}$ maka dalam takziyahpun orang yang melayat akan datang menghibur keluarga yang ditinggalkan agar ikhlas dan sabar menerima musibah kematian. Adapun nilaik keislaman yang terkandung dalam ta'ziyah yang berkaitan dengan materi ikatan hidrogen adalah kerjasama dan solidaritas sosial antar sesama muslim yang dapat memperkuat ukhuwah islamiyah

\section{Implementasi Bahan Ajar}

Pada tahap ini, bahan ajar kimia kontekstual terintegrasi keislaman yang dikembangkan diuji coba, yaitu uji coba kelompok kecil dan uji coba lapangan yang dijadikan acuan dalam melakukan proses evaluasi dan revisi.

Setelah bahan ajar dikembangkan, selanjutnya dilakukan validasi produk oleh ahli materi kimia dan agama dan ahli media kemudian dilakukan proses revisi yang disesuaikan dengan hasil validasi ahli media. ahli materi, dan ahli agama. Beberapa hal yang dinilai oleh ahli materi antara lain rasionalitas, kelayakan isi, kelayakn penyajian, kelayakan bahasa. Adapun yang dinilai oleh ahli agama antara lain: Ketepatan pengintegrasian materi dengan ayat Al-Quran dan hadis, Kesesuaian materi kimia dengan konsep keislaman, Kesesuaian materi kimia dengan nilai-nilai keislaman, Kesesuaian istilahistilah agama islam dalam materi bahan ajar, Ketepatan penulisan ayat Al-quran dan hadis yang ditampilkan dalam bahan ajar.

\section{Evaluasi Bahan Ajar}

Tahap evaluasi ini dilakukan dalam setiap tahap pengembangan yang dilakukan sehingga dapat mengetahuai perkembangan produk yang dihasilkan. Evaluasi terakhir dilakukan untuk mendapatkan tanggapan siswa terhadap bahan ajar yang dikembangkan sehingga dapat mengetahui kelayakan bahan ajar, Jika bahan ajar yang dikembangkan telah layak, maka bahan ajar tersebut dapat digunakan sebagai sumber belajar yang membantu siswa dalam kegiatan pembelajran di sekolah.

Kualitas suatu bahan ajar yang digunakan dalam pembelajaran dapat diukur melalui :(1) Hal yang langsung tampak dalam bahan ajar, yaitu format bahan ajar seperti bentuk bahan ajar secara keseluruhan yang berupa ukuran bahan ajar, sampul bahan bahan ajar, gambar-gambar yang terdapat dalam bahan ajar, serta warna-warna dalam bahan ajar; (2) Isi bahan ajar yang berupa materi-materi yang disajikan daalm bahan ajar yang perlu disesuaikan dengan kemampuan siswa yaitu jenjang perkembangan kognitif siswa, seperti bahasa yang digunakan dan ilustrasi yang ditampilkan.

Kualitas bahan ajar yang dikembangkan diperoleh dari hasil validasi ahli yaitu ahli media, ahli materi kimia, dan ahli agama serta penilaian siswa pada uji coba kelompok kecil dan uji lapangan. Proses validasi dilakukan agar menghasilkan bahan ajar dengan kriteria sangat 
baik, dimana untuk mendapatkan kriteria tersebut proses validasi setiap validator dilakukan dalam dua tahap. Adapun hasil penilaian dari masingmasing validator dan guru kimia terdapat pada tabel 3 .

Tabel 3. Hasil Penilaian Validator dan Guru Kimia

\begin{tabular}{|c|c|c|}
\hline No. & Validator & Presentase $(\%)$ \\
\hline 1. & Ahli materi kimia & 88 \\
\hline & $\begin{array}{l}\text { Ahli materi bidang } \\
\text { agama }\end{array}$ & 84 \\
\hline & Ahli media & 95 \\
\hline & Guru Kimia & 93 \\
\hline
\end{tabular}
dilakukan pada uji coba coba kelompok kecil dan uji lapangan setelah proses validasi oleh validator. Hasil penilaian siswa terdapat pada tabel 4.

Tabel 4. Hasil Penilaian Validator dan Guru Kimia

\begin{tabular}{ccc}
\hline No. & Penilaian Siswa & Presentase (\%) \\
\hline 1. & Uji kelompk kecil & 89,6 \\
2. & Uji lapangan & 96,3 \\
\hline & Tanggapan siswa terhadap bahan ajar
\end{tabular}
kimia kontekstual terintegrasi keislaman juga sangat baik. Adapaun yang dinilai siswa antara lain: teks dan tulisan, ilustrasi yang ditampilkan dalam bahan ajar, tampilan bahan ajar, gambar yang ditampilkan, kalimat yang digunakan dalam bahan ajar, kejelasan dan kemudahan dalam memahami materi bahan ajar, kejelasan petunjuk dalam bahan ajar, kelancaran penggunaan bahan ajar dalam pembelajaran, Kemudahan dalam memahami soal-soal evaluasi dalam bahan ajar Siswa sangat terbantu dalam mempelajari materi ikatan kimia. Dengan demikian, Bahan Ajar Kimia Kontekstual Terintegrasi Keislaman yang dikembangkan telah layak digunakan dalam pembelajaran kimia sehingga diharapkan dapat meningkatkan pemahaman siswa dalam belajar serta dapat meningkatkan keimanan dan ketakwaan siswa kepada Allah SWT.

\section{SIMPULAN}

Berdasarkan penilaian ahli materi, ahli agama, ahli media, guru kimia, dan siswa, maka bahan ajar kimia kontekstual dan terintegrasi keislaman yang dikembangkan sangat layak digunakan dalam pembelajaran.

Pengembangan bahan ajar kimia yang kontekstual dan terintegrasi keislaman diharapkan dapat dilakukan pada materi kimia yang lain serta menggunakan model pengembangan yang lain juga agar menghasilkan bahan ajar yang lebih baik lagi

\section{DAFTAR PUSTAKA}

Akhmad, H. (1992). Struktur Atom, Struktur Molekul, Sistem Periodik. Bandung: Citra Aditya Bakti.

Amri, S. (2010). konstruksi Pengembangan Pembelajaran. Jakarta: Prestasi Pustaka.

Arikunto, S. (2006). Prosedur Penelitian. Jakarta: Rineka Cipta.

Baum. (1980). A Life Science Approach Second Edition. New York: Macmillan Publishing.

Branch. (2009). Instructional Design: the ADDIE Approach. New York: Springer.

Chang, R. (2004). Kimia Dasar. Jakarta : Erlangga.

Effendy. (2016). Ilmu Kimia untuk Siswa SMA dan MA Kelas $X$. Malang: Indonesian Academic Publishing.

Fadhlun. (2017). Pengembangan bahan ajar Matematika yang Terintegrasi Nilai Keislaman pada Materi Aritmatika Sosial di Kelas VIII Sekolah Menengah Pertama. Lampung: IAIN Raden Intan.

Kemendikbud. (2013). Modul Pelatihan Implementasi Kurikulum 2013. Jakarta: Kemendikbud.

Komalasari, K. (2013). Pembelajaran Kontekstual: Konsep dan Aplikasi. Bandung: Refika Aditama.

Prasetiawan, W. (2008). Kimia Dasar 1. Jakarta: Cerdas Pustaka.

Prastowo, A. (2012). Pengembangan Sumber belajar. Yogyakarta: Pedagogia.

Purwanto. (2008). Ayat-ayat Semesta. Bandung: Mizan.

Purwanto, Y. (2015). Pengembangan bahan Ajar Berbasis Kontekstual pada Materi Himpunan Berbantu Video Pembelajaran. Pendidikan Matemtika FKIP Universitas Muhamadiyah Metro, Vol.4, No.1(6777).

Ramzi. (2004). Mengintegrasikan Ilmu Pengetahuan dan Ilmu Agama. Yogyakarta: Perta.

Riduwan. (2013). Pengantar statistika Sosial. Bandung: Alfabeta.

Rimbawati. (2014). Penerapan Pendekatan Kontekstual dalam Pembelajaran Tematik. Lampung: Universitas Lampung. Sanjaya, W. (2006). Strategi Pembelajaran Berorientasi Standar dan Proses 
Chemistry Education Practice, 4 (2), 2021 - 193

Qurniati

Pendiidikan. Jakarta: Kencana Prenada

Media.

Suyanti. (2010). Strategi Pembelajaran Kimia.

Yogyakarta: Graha Ilmu.

Tupamahu. (2001). Struktur Atom, Struktur

Molekul, Sistem Periodik. Bandung: Citra

Aditya Bakti.

Wibraham. (1992). Pengantar Kimia Organik dan Hayati. Bandung: ITB. 